\title{
Improving sperm banking efficiency in endangered species through the use of a sperm selection method in brown bear (Ursus arctos) thawed sperm
}

L. Anel-Lopez ${ }^{1,2^{*}}$ (D, C. Ortega-Ferrusola ${ }^{1,2}$, M. Álvarez ${ }^{1,2}$, S. Borragán ${ }^{3}$, C. Chamorro ${ }^{4}$, F. J. Peña ${ }^{5}$, J. Morrell ${ }^{6}$, L. Anel ${ }^{1,2}$ and P. de Paz ${ }^{2,7}$

\begin{abstract}
Background: Sperm selection methods such as Single Layer Centrifugation (SLC) have been demonstrated to be a useful tool to improve the quality of sperm samples and therefore to increase the efficiency of other artificial reproductive techniques in several species. This procedure could help to improve the quality of genetic resource banks, which is essential for endangered species. In contrast, these sperm selection methods are optimized and focused on farm animals, where the recovery task is not as important as in endangered species because of their higher sperm availability. The aim of this study was to evaluate two centrifugation methods $(300 \times \mathrm{g} / 20 \mathrm{~min}$ and $600 \times \mathrm{g} / 10 \mathrm{~min}$ ) and three concentrations of SLC media (Androcoll-Bear -80, 65 and 50\%) to optimise the procedure in order to recover as many sperm with the highest quality as possible. Sperm morphology could be important in the hydrodynamic relationship between the cell and centrifugation medium and thus the effect of sperm head morphometry on sperm yield and its hydrodynamic relationship were studied.

Results: The samples selected with Androcoll-Bear 65\% showed a very good yield $(53.1 \pm 2.9)$ although the yield from Androcoll-Bear $80 \%$ was lower $(19.3 \pm 3.3)$. The latter showed higher values of motility than the control immediately after post-thawing selection. However, both concentrations of colloid (65 and 80\%) showed higher values of viable sperm and viable sperm with intact acrosome than the control. After an incubation of $2 \mathrm{~h}$ at $37^{\circ} \mathrm{C}$, the samples from Androcoll-Bear $80 \%$ had higher kinematics and proportion of viable sperm with intact acrosome. In the morphometric analysis, the sperm selected by the Androcoll-Bear $80 \%$ showed a head with a bigger area which was more elongated than the sperm from other treatments.

Conclusions: We conclude that sperm selection with Androcoll-Bear at either $65 \%$ or $80 \%$ is a suitable technique that allows a sperm population with better quality than the initial sample to be obtained. We recommend the use of Androcoll-Bear 65\% since the yield is better than Androcoll-Bear $80 \%$. Our findings pave the way for further research on application of sperm selection techniques to sperm banking in the brown bear.
\end{abstract}

Keywords: Brown bear, Sperm selection, Androcoll-bear, Cryopreservation, Genetic resources bank

\footnotetext{
*Correspondence: luis.anel86@gmail.com; lanel@unileon.es

1 Animal Reproduction and Obstetrics, University of León, León, Spain

${ }^{2}$ ITRA-ULE, INDEGSAL, University of León, 24071 León, Spain

Full list of author information is available at the end of the article
} 


\section{Background}

The development of specific protocols for sperm handling adapted to endangered species, i.e., the Cantabrian brown bear (Ursus arctos) in Spain, is essential for the creation of ahigh quality genetic resource bank (GRB). In relation to bear GRB, our research group have evaluated different aspects that influence brown bear sperm quality after freezing and thawing: a species-specific extender [1], refrigeration or post-thawing incubation -thermal stress test- $[2,3]$ or using additives in the extender formulation [4].

Usually sperm samples have to be frozen in-situ because of the logistical problems related to the distance between the animals (in a zoo or their own habitat) and the laboratory. The use of selection methods may represent an important tool for improving the quality of sperm samples and removing the extender $[5,6]$, allowing us to carry out other artificial reproductive techniques such as sperm sex sorting or in vitro fertilization (IVF) [7, 8]. For success with such techniques, which are now being employed in brown bear, a high quality of sperm samples and the absence of egg yolk and glycerol are mandatory. In wild species, the logistical problems of transporting sperm samples to the laboratory in good condition are a barrier in the application of reproductive biotechnologies. One of the most important objectives of conservationist projects is to store as many high-quality samples as possible. Sperm selection optimizes the use of available space, allowing us to select useful cells (viable and motile sperm) and discard non-viable, apoptotic and non- motile sperm that impair the quality of the sample [9].

Previous studies with colloid centrifugation, using species -specific formulations of Androcoll, have reported beneficial effects in improving the motility, viability or mitochondrial activity of sperm samples, and removing dead cells, in red deer [10], boar [11], bull [12], or stallion [13], or buck [14]. In contrast, one of the main problems of the selection process with colloid centrifugation is the low yield in thawed samples. Anel-Lopez et al. [10] recovered 22 and $26 \%$ of the spermatozoa in red deer thawed semen, Garcia et al. [13] obtained yields of 20-40\% from stallion thawed semen, whereas, Jimenez Rabadan et al. [14] achieved yields of 50\% in fresh samples from buck and $14 \%$ in frozen-thawed samples.

Another factor that has been intensively studied in recent years is the sperm head morphology and its relationships with factors such as freezability [15, 16], fertility [17], or with the ability of sperm to migrate through artificial mucus [18]. The yield of sperm in a selection process could be related to the specific shape of individual sperm in the sample and their ability to penetrate the selection medium i.e. colloid, mucus etc. These differences among sperm inside the same sample could result in sperm subpopulations with different sperm motilities or a different degree of damaged nucleus. Sperm head morphology has been analysed as a fertility biomarker in various species, such as humans [19], boar [17] or sheep [20].

The aim of this study was to find an optimal procedure for the selection of frozen-thawed brown bear spermatozoa using Androcoll-Bear to separate viable spermatozoa from the extender and non-viable, non-motile cells after thawing. The effect of the density of the colloid on sperm yield, and the role of sperm head morphology on the selected sperm subpopulation were analysed.

\section{Methods}

\section{Reagents and media}

All the products used in this paper were of at least reagent grade and were acquired from Sigma (Madrid, Spain), unless otherwise stated. Fluorescence probes YO-PRO-1 and Hoechst33342 were purchased from Invitrogen (Barcelona, Spain). Stock solutions of the fluorescence probes were: PI: $7.5 \mathrm{mM}$; PNA-FITC: $0.2 \mathrm{mg} / \mathrm{mL}$; YO-PRO-1: $50 \mu \mathrm{M}$. All fluorescent stocks were prepared in DMSO - except for PI, Hoechst 33,342 and PNA-FITC, which were prepared in water - and kept at $-20{ }^{\circ} \mathrm{C}$ in the dark until needed, with the exception of the Hoechst, which was stored at $5{ }^{\circ} \mathrm{C}$. Flow cytometry equipment, software and consumables were purchased from Beckman Coulter (Fullerton, CA, USA) or Becton Dickinson (San Jose, CA, USA). The medium for cytometry assessment was bovine gamete medium (BGM-3) composed of $87 \mathrm{mM} \mathrm{NaCl}, 3.1 \mathrm{mM} \mathrm{KCl}, 2 \mathrm{mM}$ $\mathrm{CaCl} 2,0.4 \mathrm{mM} \mathrm{MgCl} 2,0.3 \mathrm{mM} \mathrm{NaH} 2 \mathrm{PO} 4,40 \mathrm{mM}$ HEPES, $21.6 \mathrm{mM}$ sodium lactate, $1 \mathrm{mM}$ sodium pyruvate, $50 \mu \mathrm{g} / \mathrm{mL}$ kanamycin, $10 \mu \mathrm{g} / \mathrm{mL}$ phenol red and $6 \mathrm{mg} / \mathrm{mL}$ BSA (pH 7.5).

For fixing samples, a $2 \%$ Glutaraldehyde solution was used, composed of BL-1 medium (glucose $14.6 \mathrm{mM}$, sodium citrate anhydrous $3.4 \mathrm{mM}$, sodium bicarbonate $2.4 \mathrm{mM}$.

\section{Animals and sperm collection}

Animal handling and electroejaculation were performed in accordance with Spanish Animal Protection Regulation RD53/2013, which conforms to European Union Regulation 2010/63/UE. All experiments were approved by the Ethical Committee for Experimentation with Animals of León University, Spain (03-02/2010).

Ejaculates from 6 sexually mature ( $\geq 6$ years old) brown bear (Ursus arctos) males were obtained by electroejaculation, during the breeding season (end of April to early July). The animals were housed in a half-freedom regimen in Cabarceno Park (Cantabria, Spain; $43^{\circ} 21^{\prime} \mathrm{N}, 3^{\circ} 50^{\prime} \mathrm{W}$; altitude: $143 \mathrm{~m}$ ), and fed with a diet based on chicken meat, bread, fruits and vegetables.

The animals were immobilized by teleanaesthesia and the electroejaculation was carried out as described by [2] Immediately after collection, the volume and concentration of each ejaculate were recorded. Sperm concentration, 
sperm motility kinematics, and urospermia content were assessed as previously described by [2]. Low motility $(<50 \%)$ or urine-contaminated $(>80 \mathrm{mg}$ urea/dL) samples were discarded. The selected ejaculates were centrifuged at $600 \times \mathrm{g}$ for $6 \mathrm{~min}$ at room temperature. The supernatants were discarded and each pellet was resuspended with the same volume of TES-Tris-Fructose (TTF) extender at room temperature (dilution 1:1), and cooled at $-0.25^{\circ} \mathrm{C} / \mathrm{min}$ to a final temperature of $5{ }^{\circ} \mathrm{C}$. The extender was prepared using TTF (300 mOsm/kg, pH 7.1); 20\% egg yolk, supplemented with 2\% EDTA, 1\% Equex (Equex STM Paste; Minitüb, Tiefenbach, Germany), $0.302 \mathrm{mg}$ penicillin G sodium salt $/ \mathrm{mL}$ and $0.625 \mathrm{mg}$ dihydrostreptomycin sesquisulfate $/ \mathrm{mL}$. The glycerol concentration was adjusted to a final concentration of $6 \%$.

\section{Sperm cryopreservation}

Sperm samples were diluted to a final concentration of $100 \times 10^{6}$ sperm $/ \mathrm{mL}$. After $2 \mathrm{~h}$ of equilibration at $5{ }^{\circ} \mathrm{C}$, $0.25 \mathrm{ml}$ straws were frozen in a programmable biofreezer (Kryo 560-16 Planer ${ }^{\mathrm{Tm}}$, Planer plc, Sunbury-On-Thames, UK) at $-20{ }^{\circ} \mathrm{C} / \mathrm{min}$ up to $-100{ }^{\circ} \mathrm{C}$, transferred to liquid nitrogen containers and stored for a minimum of one year. Thawing was performed by dropping straws in water at $65^{\circ} \mathrm{C}$ for $6 \mathrm{~s}$.

\section{Experimental design}

Seven straws from each male were thawed and pooled to avoid differences in the starting concentration. An aliquot of $150 \mu \mathrm{L}$ was used as an unselected control. Three proportions of Androcoll-Bear were assessed, at 80, 65 and 50\%.

A further 6 aliquots of $150 \mu \mathrm{L}$ were each layered on top of a column $(1 \mathrm{~mL}$ of Androcol-Bear in a $1.5 \mathrm{~mL}$ Eppendorf ${ }^{\circ}$ tube; 2 per each concentration (80, 65 and $50 \%)$ ). The centrifugation was carried out with two different protocols; CM1: $300 \mathrm{x} \mathrm{g} / 20 \mathrm{~min}$ and CM2: $600 \mathrm{x}$ $\mathrm{g} / 10 \mathrm{~min}$. The resulting sperm pellets were harvested and resuspended in $50 \mu \mathrm{L}$ of TES-Tris-Fructose. Selected samples and unselected samples were assessed, then incubated for $2 \mathrm{~h}$ at $37^{\circ} \mathrm{C}$ and re-assessed. The number of spermatozoa was counted before and after single layer centrifugation (SLC) using a Nucleocounter ${ }^{\circ}$ SP100 (Chemometec, Allerod, Denmark) to determine the yield of the separated sperm population.

\section{Computer-assisted sperm analysis}

Total motility (\%; TM), progressive motility (\%; PM), curvilinear path velocity $(\mu \mathrm{m} / \mathrm{s} ; \mathrm{VCL})$ and linearity (\%; LIN) were assessed using a CASA system (Computer Assisted Sperm Analysis), as described by [21].

Image sequences were saved and analysed afterwards using the editing facilities provided by ISAS (v. 12, Integrated Semen Analyser System; Poriser, Valencia, Spain). Sperm were considered motile when VCL $>10 \mu \mathrm{m} / \mathrm{s}$ and progressive if $\mathrm{VCL}>25$ and straightness $(\mathrm{STR})>80 \%$. The progressive sperm subpopulations were classified according to velocities as follows: Slow (VCL <25), Medium (VCL $>25$ and $<65$ ), Rapid (VCL $>65)$. Other events different from spermatozoa were removed, and settings were adjusted in each case to assure a correct track analysis.

\section{Evaluation of sperm viability, apoptotic markers and acrosomal status}

Several physiological traits (viability, apoptosis and acrosomal status) were assessed using fluorescent probes and flow cytometry, as described in a previous study Anel-Lopez et al. [21]. Spermatozoa stained in these two solutions were incubated for $10 \mathrm{~min}$ in the dark before analysis with a CyAn ADP flow cytometer (Beckman Coulter, Brea, CA, USA), equipped with semiconductor lasers emitting at $405 \mathrm{~nm}$ (violet; Hoechst 33,342) and $488 \mathrm{~nm}$ (blue; YO-PRO-1, PNA-FITC and PI). Filters used for each fluorochrome were 450/50 (blue) for Hoechst 33,342, 530/40 (green) for YO-PRO-1 and PNA-FITC and $613 / 20$ (red) for PI.

The sperm subpopulations obtained go as follow; PI $(+)$ (dead sperm), PI $(-)$ (Viable sperm), PNA-FITC $(+)$ (Acrosoma damaged), PNA-FITC (-) (Acrosoma non damaged), Yo-Pro1 $(+)$ (early permeability changes in the membrane).

\section{Morphometric assessment}

The sperm samples (before and after Androcoll-Bear) were fixed in $2 \%$ glutaraldehyde and smeared on microscope slides, air dried and then stained using Diff-Quick (QCA, Tarragona, Spain). For staining, slides were immersed for $10 \mathrm{~min}$ in solution A, for $15 \mathrm{~min}$ in solution B and then rinsed using distilled water, air dried and mounted with Entellan (Sigma-Aldrich). Samples were examined using a Nikon Eclipse E600 microscope (Nikon, Tokyo, Japan) equipped with a $\times 60$ bright field objective $(\times 500)$. An average of 200 cells in each sample were photographed using a Nikon DF1200 digital camera (Nikon, Tokyo, Japan) and the pictures were processed using the NIS Elements v.3 image analysis system. The morphometric analysis was carried out using a semi-automatic macro that allowed the operator to discard the sperm heads in the image that did not meet the technical requirements for the study (e.g. overlapping cells and the presence of staining artefacts). For each cell, the following parameters were calculated: area $\left(A ; \mu \mathrm{m}^{2}\right)$, length $(\mathrm{L} ; \mu \mathrm{m})$, perimeter $(\mathrm{P} ; \mu \mathrm{m})$, width $(\mathrm{W} ; \mu \mathrm{m})$ and elongation $(\mathrm{L}-\mathrm{W}) /(\mathrm{L}+\mathrm{W})$.

\section{Statistical analysis}

Data were analysed using the SAS ${ }^{\mathrm{Tm}}$ V.9.1. Package (SAS Institute Inc., Cary, NC, USA). Results are shown as means and standard errors of the mean. Data were tested for normality (Shapiro-Wilk test) and arcsin square-root 
transformation was used to normalise the data before analysis when necessary. Analyses of the data were carried out using linear mixed-effects models (MIXED procedure, ML method), including proportion of Androcoll-B (80, 65 and 50\%), centrifugation protocols (V1 and V2) and incubation time after thawing ( 0 vs. $2 \mathrm{~h}$ ) as fixed factors, and males as random effect. Significant fixed effects were further analysed using multiple comparisons of means with Tukey contrasts. A significance level of $P<0.05$ was used.

\section{Results}

There were no significant differences $(P>0.05)$ between centrifugation methods (CM1 and CM2) in any of the sperm parameters assessed. The centrifugation method had no effects on sperm quality, and therefore it was not considered as a weight factor.

\section{Sperm recovery after SLC}

The straws had an initial sperm concentration of $100 \times 10^{6} \mathrm{~mL}^{-1}$. After SLC, there were differences in yield $(P<0.05)$ among the different treatments (Table 1$)$. Androcoll-Bear at $80 \%$ showed the lowest values $(19.3 \pm 3.3)$ while Androcoll-Bear at $65 \%$ showed a higher recovery, being more than double that of Androcoll-Bear 80 (53.1 \pm 2.9 ). Androcoll-Bear 50 was used as a negative control showing values similar to those obtained with a conventional sperm washing centrifugation.

\section{Sperm motility}

After post-thawing selection, sperm motility was improved for TM, showing higher values $(P<0.05)$ for AndrocollBear 80 than the Control (Table 2). Neither AndrocollBear 50 nor Androcoll-Bear 65 showed differences with respect to the control for TM and PM. In the same way, Androcoll-Bear 80 showed the highest values of PM $(P<0.05)$ and the highest proportion of rapid PM sperm (Fig. 1). Other kinematic parameters such as VAP or LIN were improved significantly $(P<0.05)$ by Androcoll-Bear 80 compared to the control (Table 2).

After $2 \mathrm{~h}$ of incubation at $37^{\circ} \mathrm{C}$, the kinematics had decreased in all treatments $(P<0.05)$. Samples selected using Androcoll-Bear 80 maintained higher values of TM than the other treatments. Either Androcoll-Bear 80 or Androcoll-Bear 65 maintained higher values $(P<0.05)$ of

Table 1 Effect of the selection with different concentrations of Androcoll-Bear on yield in brown bear sperm

\begin{tabular}{ll}
\hline TREATMENT & \%YIELD \\
\hline Androcoll-Bear 50 & $79.6 \pm 1.8 ; \mathrm{A}$ \\
Androcoll-Bear 65 & $53.1 \pm 2.9 ; \mathrm{B}$ \\
Androcoll-Bear 80 & $19.3 \pm 3.3 ; \mathrm{C}$ \\
\hline
\end{tabular}

Treatments: Androcoll-Bear 50\%, Androcoll-Bear 65\% and Androcoll-Bear 80\%. Data are shown as the model-derived mean \pm s.e.m

$\left({ }^{A, B, C}, \mathrm{C}\right)$ Capital letters show differences $(P<0.05)$ among treatments
PM (Table 2) than the control. In addition, after incubation at $37{ }^{\circ} \mathrm{C}$ for $2 \mathrm{~h}$, Androcoll-Bear 80 was able to maintain a higher proportion $(P<0.05)$ of progressive rapid sperm than the control (Fig. 1). Moreover, VAP and LIN were reduced with time, but the samples selected by Androcoll-Bear 80 kept significant higher values $(P<0.05)$ than the control after the incubation (Table 2).

\section{Sperm viability, apoptosis and acrosomal status}

Post-thawing, selected samples (Androcoll-Bear 65 and Androcoll-Bear 80$)$ showed higher values $(P<0.05)$ of viable sperm than the Control (Table 3). In the same way, Androcoll-Bear 65 and Androcoll-Bear 80 samples showed higher values $(P<0.05)$ of viable sperm with intact acrosome (Table 3) than the control. Meanwhile, AndrocollBear 50 did not show any difference to the control, either for viability or for viable sperm with intact acrosome. No differences were observed in the percentage of apoptotic cells just after thawing for any treatment (Table 3).

After $2 \mathrm{~h}$ of incubation, all treatments showed lower values $(P<0.05)$ of viability and viable sperm with intact acrosome (Table 3). In contrast, no differences were observed in the percentage of apoptotic sperm after incubation. Androcoll-Bear 80 samples maintained higher values $(P<0.05)$ of viable sperm and viable sperm with intact acrosome than the Control (Table 3). There were no differences among treatments in the percentage of apoptotic sperm (Table 3).

\section{Sperm morphometry}

The sperm samples selected with Androcoll-Bear 80 showed significantly $(P<0.05)$ higher values for all the morphometric parameters assessed (Area, length, width, perimeter and elongation) than the control samples (Table 4). In contrast, samples selected with AndrocollBear 65 showed significantly lower values $(P<0.05)$ than the Control for the area, length and width. Meanwhile, Androcoll-Bear 50 showed similar results to the control for the perimeter, length and elongation $(P>0.05)$ and lower values for area and width $(P<0.05)$ (Table 4$)$.

\section{Discussion}

The effect of the selection with different proportions of Androcoll-Bear on bear sperm quality and yield were assessed to optimize the protocol to be used with Androcoll-Bear in the selection of brown bear (Ursus arctos) sperm and then improving the sperm banking efficiency.

The Cantabric population of brown bear in Spain is endangered and sperm samples are very difficult to obtain; for this reason, every spermatozoon is valuable. In order to optimize sperm selection to get the best quality and the highest yield, three concentrations of AndrocollBear and two centrifugation methods were tested. No 
Table 2 Effect of the selection with different concentrations of Androcoll-Bear on sperm motility in brown bear sperm

\begin{tabular}{|c|c|c|c|c|c|}
\hline TIME & TREATMENT & $\%$ TM & $\% \mathrm{PM}$ & VAP & LIN \\
\hline \multirow[t]{4}{*}{$\overline{\mathrm{Oh}}$} & Control & $68.4 \pm 3.8 \mathrm{~A}$ & $37.1 \pm 0.8 \mathrm{~A}$ & $53.4 \pm 2.2 \mathrm{~A}$ & $39.8 \pm 2.2 \mathrm{~A}$ \\
\hline & A50 & $64.6 \pm 4.2 \mathrm{~A}$ & $37.2 \pm 1.9 \mathrm{~A}$ & $53.1 \pm 2.8 \mathrm{~A}$ & $42.6 \pm 1.6 \mathrm{~A}$ \\
\hline & A65 & $72.5 \pm 4.1 \mathrm{~A}$ & $42.3 \pm 2.6 \mathrm{~A}$ & $59.1 \pm 3.5 \mathrm{~A}$ & $43.3 \pm 1.9 \mathrm{~A}$ \\
\hline & A80 & $84.7 \pm 1.6^{*} ; \mathrm{A}$ & $58 \pm 2.4 *$;A & $71.6 \pm 3.3^{*} ; \mathrm{A}$ & $50.9 \pm 2.5 * \mathrm{~A}$ \\
\hline \multirow[t]{4}{*}{$2 \mathrm{~h}$} & Control & $39.1 \pm 4.5$ B & $18.4 \pm 3 B$ & $32.4 \pm 3.1 \mathrm{~B}$ & $33 \pm 1.3 B$ \\
\hline & A50 & $41.5 \pm 5.3 \mathrm{~B}$ & $23.9 \pm 3.2 \mathrm{~B}$ & $35.7 \pm 3.1 \mathrm{~B}$ & $37.5 \pm 1.5 \mathrm{~B}$ \\
\hline & A65 & $57.3 \pm 5.1 \mathrm{~B}$ & $36.1 \pm 3.6^{*} ; \mathrm{A}$ & $42.1 \pm 3.4 \mathrm{~B}$ & $39.7 \pm 1.6 \mathrm{~A}$ \\
\hline & A80 & $74.9 \pm 3.6^{*} ; B$ & $50.7 \pm 3{ }^{*} ; \mathrm{A}$ & $49.1 \pm 3 * ; B$ & $40.6 \pm 2.1 * ; B$ \\
\hline
\end{tabular}

The table shows: total motility (\%TM), progressive motility (\%PM), velocity average pathway (VAP) and linearity (LIN). Time: Just after thawing (0 $\mathrm{h}$ ) and after an incubation of $2 \mathrm{~h}$ at $37{ }^{\circ} \mathrm{C}(2 \mathrm{~h}$ ). Treatments: Androcoll-Bear 50\% (A50), Androcoll-Bear 65\% (A65) and Androcoll-Bear 80\% (A80). Data shown are the model-derived mean \pm s.e.m

$(*)$ Asterisks show differences $(P<0.05)$ between Androcoll proportion and its Control

$\left({ }^{A}, \mathrm{~B}\right)$ Capital letters show differences $(P<0.05)$ for the same treatment between time $(0$ and $2 \mathrm{~h})$

differences were observed between centrifugation methods, and therefore we recommend CM2 since it takes half the time and achieves the same sperm quality and yield.

Some species-specific colloids of Androcoll have been tested under different handling conditions, obtaining varied results. Our results show an improvement in sperm quality with Androcoll-Bear 65 and especially with Androcoll-Bear 80. These results are in concordance with Anel-Lopez et al. [10] who found several improvements in the sperm quality (sperm motility, cells with intact acrosomes, sperm viability and cells with mitochondrial activity) from red deer after thawing and selecting, in sperm samples obtained either by electroejaculation or post-mortem. In addition, these improvements were maintained after an incubation of $2 \mathrm{~h}$ at $37{ }^{\circ} \mathrm{C}$ compared to the control, in agreement with our results with Androcoll-Bear 80 in the present study. In the same way, positive effects on sperm quality were reported by [13] in stallion semen.

However, some authors have reported an absence of effect in individual parameters when selecting sperm samples with Androcoll. Bucci et al. [22] working with boar sperm did not observe any significant difference between the control and the selected samples in terms of percentage of damaged acrosomes, although other parameters of sperm quality were improved.

The most important problem when using sperm selection methods is the low yield, especially with frozen-thawed samples [10, 14]. Referring to yield, there were differences among colloid proportions. Androcoll-Bear 65 samples showed good recovery and an improvement in sperm

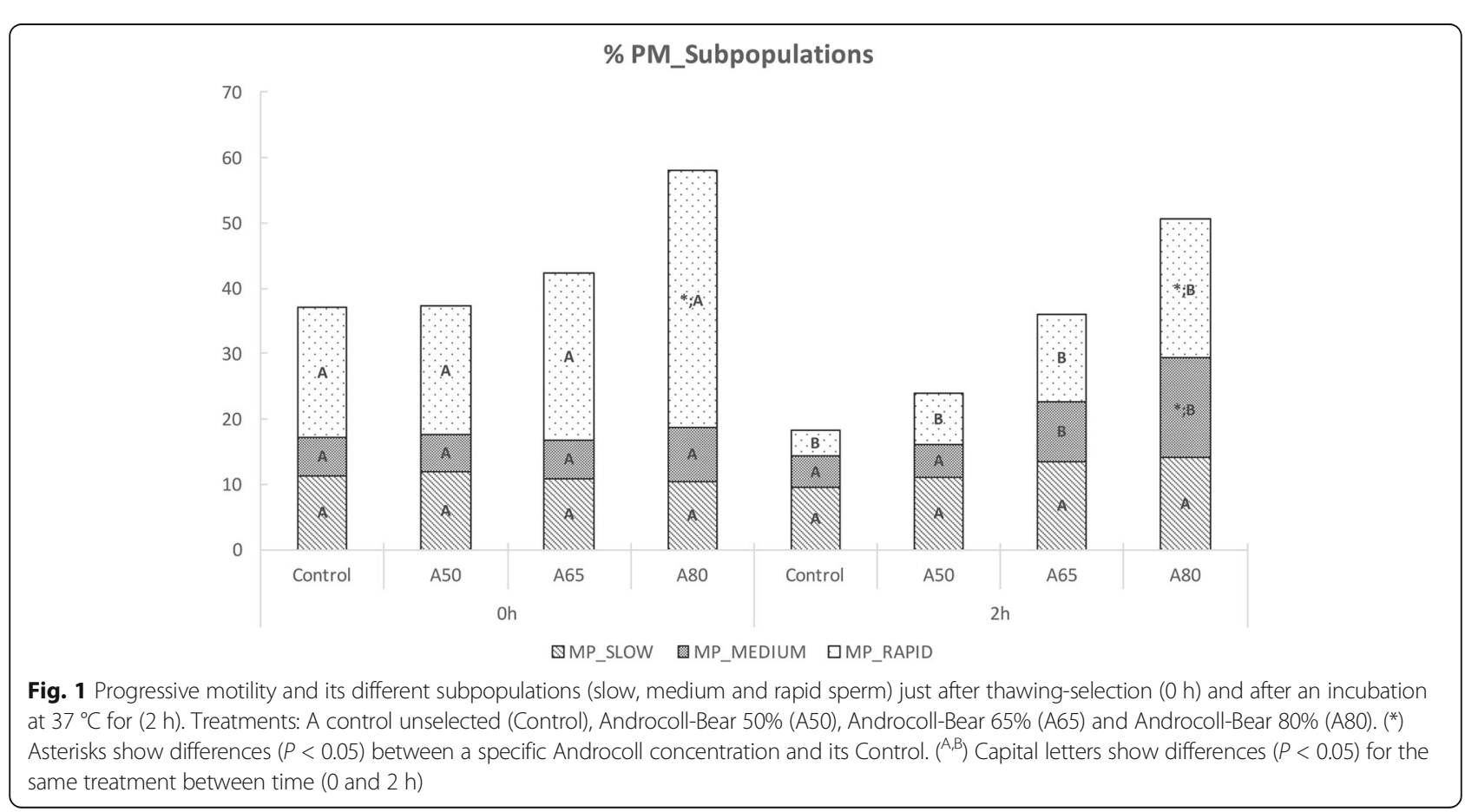


Table 3 Effect of the selection with different concentrations of Androcoll-Bear on sperm membrane and acrosomal status

\begin{tabular}{lllll}
\hline TIME & TREATMENT & \%Viab & \%Apoptosis & \%Viable_Acro \\
\hline o h & Control & $46.7 \pm 4 \mathrm{~A}$ & $24.2 \pm 4.3 \mathrm{~A}$ & $75.4 \pm 3.6 \mathrm{~A}$ \\
& A50 & $58.4 \pm 2.7 \mathrm{~A}$ & $16 \pm 2.4 \mathrm{~A}$ & $81.6 \pm 2.1 \mathrm{~A}$ \\
& A65 & $73.9 \pm 2.4 * ; \mathrm{A}$ & $15 \pm 2.8 \mathrm{~A}$ & $88 \pm 1.4{ }^{*} ; \mathrm{A}$ \\
& A80 & $78.1 \pm 2.3 *$;A & $15.3 \pm 2.6 \mathrm{~A}$ & $93 \pm 1.2{ }^{*} ; \mathrm{A}$ \\
$\mathrm{2h}$ & Control & $31.7 \pm 3.9 \mathrm{~B}$ & $24.1 \pm 5.5 \mathrm{~A}$ & $55.9 \pm 5.2 \mathrm{~B}$ \\
& A50 & $45.6 \pm 3.6 \mathrm{~B}$ & $16.9 \pm 1.9 \mathrm{~A}$ & $64.1 \pm 4 \mathrm{~B}$ \\
& A65 & $50.7 \pm 5.1 * ; B$ & $16.8 \pm 1.7 \mathrm{~A}$ & $68.4 \pm 4.3 \mathrm{~B}$ \\
& A80 & $56.1 \pm 4.2 * ; B$ & $19.6 \pm 2 \mathrm{~A}$ & $75.9 \pm 4.2$ *B \\
\hline
\end{tabular}

The table shows: viability (\%Viab), apoptosis (\%Apoptosis) and viable sperm with intact acrosome (\%Viable_Acro). Time: immediately after thawing $(0 \mathrm{~h})$ and after an incubation of $2 \mathrm{~h}$ at $37^{\circ} \mathrm{C}(2 \mathrm{~h})$. Treatments: Androcoll-Bear $50 \%$ (A50), Androcoll-Bear 65\% (A65) and Androcoll-Bear 80\% (A80). Data shown are the model-derived mean \pm s.e.m

$\left({ }^{*}\right)$ Asterisks show differences $(P<0.05)$ between a specific Androcoll-Bear proportion and its Control

$(\mathrm{A}, \mathrm{B})$ Capital letters show differences $(P<0.05)$ for the same treatment between time ( 0 and $2 \mathrm{~h}$ )

viability. In addition, the sperm maintained higher values of viability not only immediately after selection, but also after incubation. This formulation Androcoll-Bear 65 could help us to optimize the space in GRBs, since non-viable sperm are discarded. Moreover, it could improve processes such as sperm sex sorting. When sperm samples are sorted, the presence of a high percentage of non-viable sperm compromises the efficiency of the sorting process, increasing the time required to sort the sample, which impairs its quality, and decreases the efficiency of this technique [23]. The use of selection methods such as single layer centrifugation enables all of the extender to be removed from the sample as well as facilitating the application of other techniques such as sperm sex sorting or in vitro fertilization $[5,6]$. Removal of extender is mandatory for success with techniques such as sperm sex-sorting, since the egg yolk causes opacity in the media surrounding the sperm cells, compromising the uniformity of the staining, interfering with laser excitation of the Hoechst-33,342 and with light transmission to the detectors $[24,25]$, and therefore resulting in a poor resolution of $\mathrm{X}$ - and Y-chromosome bearing sperm population [26].

Finally, Androcoll-Bear 80 showed the lowest recovery in this experiment, although improving all the sperm parameters assessed immediately after selection. This formulation (Androcoll-Bear 80) could be optimal in processes where a very high sperm quality, especially sperm motility, is required for success such as IVF [27]. Mitochondrial activity is known to be related with sperm motility and a relationship with fertility has been demonstrated [28, 29]. Cooling and freezing causes stress to spermatozoa and the mitochondria are the sperm structure most sensitive to this damage [30]; thus, the effect of selection bear spermatozoa using Androcoll-Bear on mitochondrial membrane potential will be considered in future studies.

The sperm population selected with Androcoll-Bear 80 had the highest values for area, length, width and elongation. This observation indicates that the sperm selected with the highest proportion of Androcoll were the biggest, the most hydrodynamic and the fastest of the whole sample. Therefore, according to [18], we can hypothesize that these selected samples could penetrate better and deeper into the female reproductive tract. Previous studies carried out in red deer showed that the lower the sperm head area in fresh samples, the greater the sperm cryoresistance [31]. These authors not only found a correlation between area and freezability but also between shape and freezability. This factor could be important since the distance from the side of the cell to the centre will determine the freezing velocity, being higher with elongation. In this context, the selection with Androcoll-Bear 80 in the present study resulted in the highest yield the highest elongation, potentially indicating better freezability.

Artificial insemination in this species is not yet developed because of many logistical and physiological issues that cannot be solved at present. In the absence of fertility trials, our further investigations will focus on the detection of predictive parameters of sperm quality such as: oxidative stress markers; 8-iso-PGF2alfa, 8-OHguanosine, 4-hydroxynonenaloxidation or the presence of active caspase 3 and 7 [32, 33]. Martin-Muñoz et al. [33] demonstrated assessing these markers to determine the differential effect of ROS during cryopreservation on stallion sperm and the importance of ROS homeostasis in the selection of ejaculates for freezing. The elimination of non-viable sperm from a sample could be important in ROS homeostasis since the dead sperm are known to have a negative effect

Table 4 Effect of the selection with different concentrations of Androcoll-Bear on sperm morphology

\begin{tabular}{llllll}
\hline & Area & Perimeter & Length & Width & Elongation \\
\hline Control & $19.78 \pm 0.06 \mathrm{~A}$ & $16.03 \pm 0.02 \mathrm{~A}$ & $6.01 \pm 0.01 \mathrm{~A}$ & $3.29 \pm 0.01 \mathrm{~A}$ & $1.3934 \pm 0.0024 \mathrm{~A}$ \\
$\mathrm{~A} 50$ & $19.55 \pm 0.04 \mathrm{~B}$ & $15.96 \pm 0.02 \mathrm{AB}$ & $5.99 \pm 0.01 \mathrm{AB}$ & $3.26 \pm 0 \mathrm{~B}$ & $1.3910 \pm 0.0016 \mathrm{AB}$ \\
$\mathrm{A} 65$ & $19.48 \pm 0.04 \mathrm{~B}$ & $15.93 \pm 0.02 \mathrm{~B}$ & $5.98 \pm 0.01 \mathrm{~B}$ & $3.25 \pm 0 \mathrm{~B}$ & $1.3985 \pm 0.0016 \mathrm{AC}$ \\
A80 & $20.21 \pm 0.03 \mathrm{C}$ & $16.2 \pm 0.01 \mathrm{C}$ & $6.08 \pm 0.01 \mathrm{C}$ & $3.32 \pm 0 \mathrm{C}$ & $1.4007 \pm 0.0015 \mathrm{C}$ \\
\hline
\end{tabular}

The table shows: Area $\left(\mu \mathrm{m}^{2}\right)$, Perimeter $(\mu \mathrm{m})$, Length $(\mu \mathrm{m})$, Width $(\mu \mathrm{m})$, Elongation.

Samples were assessed after thawing and after selection. Treatments: Androcoll-Bear 50\% (A50), Androcoll-Bear 65\% (A65) and Androcoll-Bear $80 \%$ (A80). Data are shown the model-derived mean \pm s.e.m

$\left({ }^{A}, \mathrm{~B}\right)$ Capital letters show differences $(P<0.05)$ 
on the viable subpopulation [9]. In addition, Roca et al. [34] showed that high proportions of dead sperm in raw semen samples before and during freezing induce significantly increased ROS generation and nuclear DNA fragmentation in frozen-thawed sperm. This is important since it is known that lipid peroxidation is related to "apoptosis-like" changes [35]. In this context, removing the dead sperm by selection with Androcoll-Bear may play an important role in improving cryosurvival rates not only after thawing, but also after incubation.

\section{Conclusions}

In conclusion, sperm selection by Androcoll-Bear at proportions of $80 \%$ and $65 \%$ in brown bear sperm samples after thawing could be a useful tool. Androcoll-Bear 65 can improve the viability while giving good recoveries after thawing; meanwhile, Androcoll-Bear 80 resulted in a very high sperm quality but lower yield. In our opinion, Androcoll-Bear 65 would be optimal due to the higher difference in the recovery than Androcoll-Bear 80. Our findings pave the way for further research on application of sperm selection techniques to sperm banking in wild species and especially in brown bear.

\section{Additional files}

Additional file 1: Data from the sperm quality parameters assessed. (PDF $39 \mathrm{~kb}$ )

Additional file 2: Data from sperm morphometry assessment. (PDF $1413 \mathrm{~kb}$ )

\section{Abbreviations}

\%; LIN: Linearity; \%; PM: Progressive Motility; \%; TM: Total Motility; (E) (L - W)/ $(L+W)$ : Elongation; A; $\mu m^{2}$ : Area; BGM-3: Bovine Gamete Medium; BSA: Bovine Serum Albumin; CASA: Computer Assisted Sperm Analysis; CM: Centrifugation Method; GRB: Genetic Resource Banks; IVF: in vitro fertilization; L; $\mu$ m: Length: P; $\mu \mathrm{m}$ : Perimeter; SLC: Single Layer Centrifugation; STR: Straightness; TTF: TES-Tris-Fructose; VAP: Average Path Velocity; W; $\mu \mathrm{m}$ : Width; $\mu \mathrm{m} / \mathrm{s}$; VCL: Curvilinear Path Velocity

\section{Acknowledgements}

The authors thank Miguel Angel Marañon, Miguel Angel Prieto, the Game keepers of the Cabarceno Nature Park, Susana Gomes Alves, Elena Lopez Urueña, Patrocinio Villafañe, Patricia Manrique and Carmen MartinezRodriguez.

\section{Funding}

This work was supported in part by MINECO (CGL2013-48255-R) and Cantur S.A. Luis Anel-Lopez was supported by MINECO (CGL2013-48255-R). C ortega-Ferrusola is supported by a postdoctoral grant from "Ministerio de Economía y Competitividad "Juan de la Cierva" IJCl-2014-21671.

\section{Availability of data and materials}

All data generated or analysed during the current study are included in this published article and its Additional files 1 and 2 .

\section{Authors' contributions}

$A L, d P P$ designed the experiment. A-LL, AG, O-FC, BS, CC, PFJ collected the experimental data (designing the animal manipulation and sperm sperm assessment). A-LL and O-FC and AM analysed the data and write the paper $\mathrm{AL}, \mathrm{dPP}$ and $\mathrm{MJ}$ contributed reagents/materials/analytical tools. dPP, AL, PFJ and $\mathrm{MJ}$ revised and approved the final manuscript. All authors read and approved the final manuscript.

\section{Ethics approval}

Animal handling and electroejaculation were performed in accordance with Spanish Animal Protection Regulation RD53/2013, which conforms to European Union Regulation 2010/63/UE. All experiments were approved by the Ethical Committee for Experimentation with Animals of León University, Spain (03-02/2010).

\section{Consent for publication}

Not applicable.

\section{Competing interests}

J.M. Morrell is the inventor of Androcoll and is a patent holder.

\section{Publisher's Note}

Springer Nature remains neutral with regard to jurisdictional claims in published maps and institutional affiliations.

\section{Author details}

${ }^{1}$ Animal Reproduction and Obstetrics, University of León, León, Spain. ${ }^{2}$ ITRA-ULE, INDEGSAL, University of León, 24071 León, Spain. ${ }^{3}$ Cabárceno Park, Cantabria, Spain. ${ }^{4}$ Veterinary Anatomy, University of Leon, 24071 León, Spain. ${ }^{5}$ Laboratory of Equine Reproduction and Equine Spermatology, Veterinary Teaching Hospital, University of Extremadura, Cáceres, Spain. ${ }^{6}$ Swedish University of Agricultural Sciences (SLU), Clinical Sciences, Uppsala, Sweden. ${ }^{7}$ Molecular Biology (Cell Biology), University of León, León, Spain.

Received: 17 February 2017 Accepted: 20 June 2017

Published online: 26 June 2017

\section{References}

1. Anel L, Gomes-Alves S, Alvarez M, Borragan S, Anel E, Nicolas M, et al. Effect of basic factors of extender composition on post-thawing quality of brown bear electroejaculated spermatozoa. Theriogenology. 2010;74:643-51. doi:10.1016/j.theriogenology.2010.03.004.

2. López-Urueña E, Alvarez M, Gomes-Alves S, Martínez-Rodríquez C, Borragan S, Anel-López L, et al. Tolerance of brown bear spermatozoa to conditions of pre-freezing cooling rate and equilibration time. Theriogenology. 2014;81: 1229-38. doi:10.1016/j.theriogenology.2014.02.004.

3. López-Urueña E, Alvarez M, Gomes-Alves S, Anel-López L, MartínezRodríguez C, Manrique P, et al. Optimization of conditions for long-term prefreezing storage of brown bear sperm before cryopreservation. Theriogenology. 2015;84:1161-71. doi:10.1016/j.theriogenology.2015.06.017.

4. Alvarez-Rodríguez M, Alvarez M, Borragan S, Martinez-Pastor F, Holt WW, Fazeli A, et al. The addition of heat shock protein HSPA8 to cryoprotective media improves the survival of brown bear (Ursus arctos) spermatozoa during chilling and after cryopreservation. Theriogenology. 2013;79:541-50. doi:10.1016/j.theriogenology.2012.11.006.

5. Hollinshead FK, Evans G, Evans KM, Catt SL, Maxwell WM, O'Brien JK. Birth of lambs of a pre-determined sex after in vitro production of embryos using frozen-thawed sex-sorted and re-frozen-thawed ram spermatozoa. Reproduction. 2004;127:557-68.

6. Morton KM, Rowe AM, Maxwell WMC, Evans G. In vitro and in vivo survival of bisected sheep embryos derived from frozen-thawed unsorted, and frozen-thawed sex-sorted and refrozen-thawed ram spermatozoa. Theriogenology. 2006;65:1333-45.

7. Anel-López L, García-Álvarez O, Parrilla I, Del Olmo D, Fernández-Santos MR, Soler AJ, et al. The effect of oxidative stress on thawed bulk-sorted red deer sperm. Reprod Domest Anim. 2016:1-8. doi:10.1111/rda.12694.

8. Thuwanut $\mathrm{P}$, Chatdarong K, Bergqvist A-S, Söderquist L, Thiangtum K, Tongthainan $D$, et al. The effects of antioxidants on semen traits and in vitro fertilizing ability of sperm from the flat-headed cat (Prionailurus planiceps). Theriogenology. 2011;76:115-25. doi:10.1016/j.theriogenology.2011.01.024.

9. Roca J, Parrilla I, Gil MA, Cuello C, Martinez EA, Rodriguez-Martinez H. Nonviable sperm in the ejaculate: lethal escorts for contemporary viable sperm. Anim Reprod Sci. 2016;169:24-31. doi:10.1016/j.anireprosci.2016.02.028.

10. Anel-López L, Martínez-Rodríguez C, Soler AJ, Fernández-Santos MR, Garde $\mathrm{JJ}$, Morrell JM. Use of Androcoll-S after thawing improves the quality of electroejaculated and epididymal sperm samples from red deer. Anim Reprod Sci. 2015;158:68-74. doi:10.1016/j.anireprosci.2015.04.009.

11. Martinez-Alborcia MJ, Morrell JM, Gil MA, Barranco I, Maside C, Alkmin DV, et al. Suitability and effectiveness of single layer centrifugation using 
Androcoll-P in the cryopreservation protocol for boar spermatozoa. Anim Reprod Sci. 2013;140:173-9. doi:10.1016/j.anireprosci.2013.06.015.

12. Goodla L, Morrell JM, Yusnizar Y, Stålhammar H, Johannisson A. Quality of bull spermatozoa after preparation by single-layer centrifugation. J Dairy Sci. 2014;97:2204-12. doi:10.3168/jds.2013-7607.

13. Macías García B, González Fernández L, Morrell JM, Ortega Ferrusola C, Tapia JA Rodriguez Martínez $\mathrm{H}$, et al. Single-layer centrifugation through colloid positively modifies the sperm subpopulation structure of frozen-thawed stallion spermatozoa. Reprod Domest Anim. 2009;44:523-6. doi:10.1111/j.1439-0531.2008.01276.x.

14. Jiménez-Rabadán P, Morrell JM, Johannisson A, Ramón M, García-Álvarez O, Maroto-Morales A, et al. Single layer centrifugation (SLC) improves sperm quality of cryopreserved Blanca-Celtibérica buck semen. Anim Reprod Sci. 2012;136:47-54. doi:10.1016/j.anireprosci.2012.09.012.

15. Ramón M, Pérez-Guzmán MD, Jiménez-Rabadán P, Esteso MC, GarcíaÁlvarez O, Maroto-Morales A, et al. Sperm cell population dynamics in ram semen during the cryopreservation process. PLoS One. 2013;8 e59189. doi:10.1371/journal.pone.0059189.

16. Núñez-Martínez I, Moran JM, Peña FJ. Sperm indexes obtained using computerassisted morphometry provide a forecast of the freezability of canine sperm. Int J Androl. 2007;30:182-9. doi:10.1111/j.1365-2605.2007.00743.x.

17. Hirai M, Boersma A, Hoeflich A, Wolf E, Foll J, Aumüller TR, et al. Objectively measured sperm motility and sperm head morphometry in boars (Sus scrofa): relation to fertility and seminal plasma growth factors. J Androl. 2001;22:104-10

18. Martínez-Rodríguez C, Alvarez M, López-Urueña E, Gomes-Alves S, AnelLópez L, Tizado JE, et al. Head morphology of ram spermatozoa is associated with their ability to migrate in vitro and correlates with fertility. Reprod Fertil Dev. 2015. doi:10.1071/RD15022.

19. Kruger TF, DuToit TC, Franken DR, Acosta AA, Oehninger SC, Menkveld R, et al. A new computerized method of reading sperm morphology (strict criteria) is as efficient as technician reading. Fertil Steril. 1993;59:202-9.

20. de Paz P, Mata-Campuzano M, Tizado EJ, Álvarez M, Álvarez-Rodríguez M, Herraez $\mathrm{P}$, et al. The relationship between ram sperm head morphometry and fertility depends on the procedures of acquisition and analysis used Theriogenology. 2011;76:1313-25. doi:10.1016/j.theriogenology.2011.05.038.

21. Anel-López L, Alvarez-Rodríguez M, García-Álvarez O, Alvarez M, Maroto-Morales $A$, Anel $L$, et al. Reduced glutathione and Trolox (vitamin E) as extender supplements in cryopreservation of red deer epididymal spermatozoa. Anim Reprod Sci. 2012;135:37-46. doi:10.1016/j.anireprosci.2012.09.001.

22. Bucci D, Spinaci M, Morrell J, Vallorani C, Tamanini C, Guidetti R, et al. Effects of single layer centrifugation with Androcoll-P on boar sperm. Anim Reprod Sci. 2013;138:276-81. doi:10.1016/j.anireprosci.2013.02.020.

23. Clulow JR, Evans G, Morris LHA, Maxwell WMC. Factors influencing the "sortability" of stallion spermatozoa into X-and Y-chromosome bearing populations. Anim Reprod Sci. 2009;113:220-8. doi:10.1016/j.anireprosci.2008.08.019.

24. Johnson LA, Welch GR. Sex preselection: high-speed flow cytometric sorting of $X$ and $Y$ sperm for maximum efficiency. Theriogenology. 1999;52:1323-41. doi:10.1016/50093-691X(99)00220-4.

25. Morris LHA. Challenges facing sex preselection of stallion spermatozoa. Anim Reprod Sci. 2005;89:147-57. http://dx.doi.org/10.1016/j.anireprosci. 2005.06.024

26. Gibb Z, Morris LHA, Maxwell WMC, Grupen CG. Use of a defined diluent increases the sex-sorting efficiency of stallion sperm. Theriogenology 2011 75:610-619. http://dx.doi.org/10.1016/j.theriogenology.2010.10.001.

27. Donnelly ET, Lewis SEM, McNally JA, Thompson W. In vitro fertilization and pregnancy rates: the influence of sperm motility and morphology on IVF outcome. Fertil Steril. 1998;70:305-14. doi:10.1016/S0015-0282(98)00146-0.

28. Kasai T, Ogawa K, Mizuno K, Nagai S, Uchida Y, Ohta S, et al. Relationship between sperm mitochondrial membrane potential, sperm motility, and fertility potential. Asian J Androl. 2002;4:97-104.

29. Love CC. Relationship between sperm motility, morphology and the fertility of stallions. Theriogenology. 2011;76:547-57. doi:10.1016/j.theriogenology. 2011.03.007.

30. García BM, Moran AM, Fernández LG, Ferrusola CO, Rodriguez AM, Bolaños $J M G$, et al. The mitochondria of stallion spermatozoa are more sensitive than the plasmalemma to osmotic-induced stress: role of c-Jun N-terminal kinase (JNK) pathway. J Androl. n.d.:33:105-13. doi:10.2164/jandrol.110.011957.

31. Esteso MC, Soler AJ, Fernández-Santos MR, Quintero-Moreno AA, Garde JJ. Functional significance of the sperm head morphometric size and shape for determining freezability in iberian red deer (Cervus elaphus hispanicus) epididymal sperm samples. J Androl. 2006;27:662-70. doi:10.2164/jandrol.106.000489.

32. Gallardo Bolaños JM, Balao da Silva CM, Martín Muñoz P, Morillo Rodríguez A, Plaza Dávila M, Rodríguez-Martínez H, et al. Phosphorylated AKT preserves stallion sperm viability and motility by inhibiting caspases 3 and 7. Reproduction. 2014;148:221-35. doi:10.1530/REP-13-0191.

33. Martin Muñoz P, Ortega Ferrusola C, Anel Lopez L, Del Petre C, Alvarez Garcia M, de Paz CP, et al. Caspase 3 activity and Lipoperoxidative status in raw semen predict the outcome of cryopreservation of stallion spermatozoa. Biol Reprod. 2016;3 doi:10.1095/biolreprod.116.139444.

34. Roca J, Martinez-Alborcia MJ, Gil MA, Parrilla I, Martinez EA. Dead spermatozoa in raw semen samples impair in vitro fertilization outcomes of frozen-thawed spermatozoa. Fertil Steril. 2013;100:875-81. doi:10.1016/j.fertnstert.2013.05.020.

35. Ortega Ferrusola C, González Fernández L, Morrell JM, Salazar Sandoval C Macías García B, Rodríguez-Martinez H, et al. Lipid peroxidation, assessed with BODIPY-C11, increases after cryopreservation of stallion spermatozoa, is stallion-dependent and is related to apoptotic-like changes. Reproduction. 2009:138:55-63. doi:10.1530/REP-08-0484.

\section{Submit your next manuscript to BioMed Central and we will help you at every step:}

- We accept pre-submission inquiries

- Our selector tool helps you to find the most relevant journal

- We provide round the clock customer support

- Convenient online submission

- Thorough peer review

- Inclusion in PubMed and all major indexing services

- Maximum visibility for your research

Submit your manuscript at www.biomedcentral.com/submit
( Biomed Central 